\title{
A novel educational tool for teaching ocular ultrasound
}

This article was published in the following Dove Press journal:

Clinical Ophthalmology

22 June 2011

Number of times this article has been viewed

\section{MS Mustafa' \\ J Montgomery² \\ HR Atta'}

'Department of Ophthalmology, Aberdeen Royal Infirmary, UK;

${ }^{2}$ Medi-CAL, College of Life Sciences and Medicine, University of Aberdeen, Foresterhill, Aberdeen, UK
Correspondence: MS Mustafa Eye Out Patient Department, Aberdeen Royal Infirmary, Foresterhill, Aberdeen, AB25 2ZN, United Kingdom

Tel +44 01224552543

Fax +44 0I 224551390

Email mmustafa2@nhs.net
Abstract: Ocular ultrasound is now in increasing demand in routine ophthalmic clinical practice not only because it is noninvasive but also because of ever-advancing technology providing higher resolution imaging. It is however a difficult branch of ophthalmic investigations to grasp, as it requires a high skill level to interface with the technology and provide accurate interpretation of images for ophthalmic diagnosis and management. It is even more labor intensive to teach ocular ultrasound to another fellow clinician. One of the fundamental skills that proved difficult to learn and teach is the need for the examiner to "mentally convert" 2-dimensional B-scan images into 3-dimensional (3D) interpretations. An additional challenge is the requirement to carry out this task in real time. We have developed a novel approach to teach ocular ultrasound by using a novel 3D ocular model. A 3D virtual model is built using widely available, open source, software. The model is then used to generate movie clips simulating different movements and orientations of the scanner head. Using Blender, Quicktime motion clips are choreographed and collated into interactive quizzes and other pertinent pedagogical media. The process involves scripting motion vectors, rotation, and tracking of both the virtual stereo camera and the model. The resulting sequence is then rendered for twinned right- and left-eye views. Finally, the twinned views are synchronized and combined in a format compatible with the stereo projection apparatus. This new model will help the student with spatial awareness and allow for assimilation of this awareness into clinical practice. It will also help with grasping the nomenclature used in ocular ultrasound as well as helping with localization of lesions and obtaining the best possible images for echographic diagnosis, accurate measurements, and reporting.

Keywords: ophthalmic, ultrasound, teaching, 3D, images, education

\section{Introduction}

Current ophthalmic simulators demonstrate the equipment setup and 3-dimensional (3D) image perception in a $2 \mathrm{D}$ environment. However they do not simulate the $3 \mathrm{D}$ nature of the eye so that the trainee does not appreciate the structures within the eye in true $3 \mathrm{D}$, and therefore depth perception and spatial awareness are a problem. Depth perception and spatial awareness are very important in that manipulation of instruments within the eye by the examiner involves distances that are microscopic.

It is critical that ophthalmologists learn in three dimensions for procedures. In ocular ultrasound it is important to know where the resultant ultrasound beam is being placed according to probe position and hence the structures being examined. The most challenging aspect of ocular B-scan ultrasound is the conversion, by the operator, of $2 \mathrm{D}$ slice of image into $3 \mathrm{D}$ interpretations. This also needs to be realized in real time in 


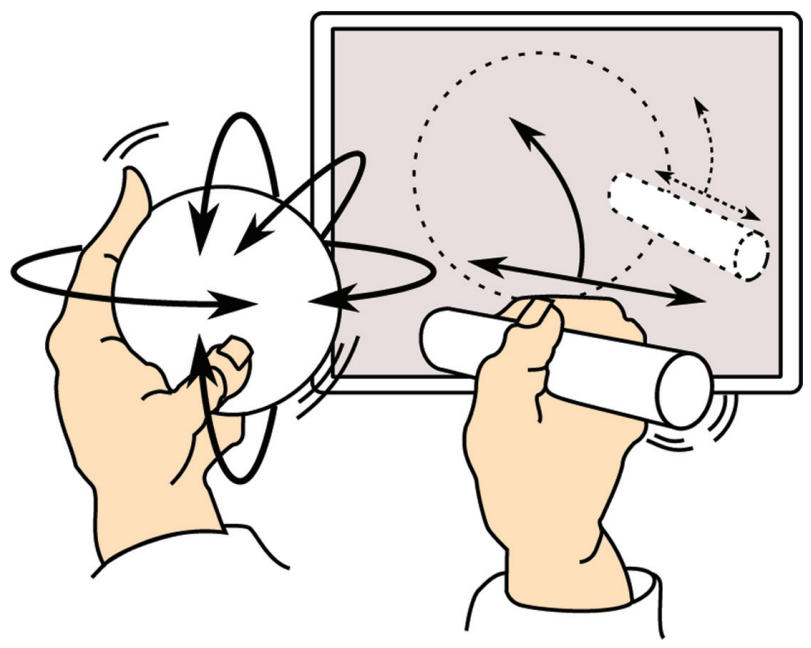

Figure I Proposed solution for teaching ocular ultrasound.

order to formulate an echographic diagnostic interpretation. In photocoagulation of the retina and YAG laser capsulotomy it is important to know exactly where and at what depth to aim the laser so as not to damage adjacent structures that can potentially have blinding consequences in real patient situations.

Use of 3D models will provide a safer environment in which clinicians can learn. Hence patients will not need to have procedures done by less experienced clinicians until they are deemed competent by way of learning from these models.

There is no current technology that can simulate the procedure in true $3 \mathrm{D}$ to give the ophthalmologist even more insight into the complexity of the procedure they are simulating.

We have studied extensively 3D computer technology and its use in teaching medical procedures. ${ }^{1-6}$

The proposed solution is real 3D and the team has developed an eye model that can be manipulated in 3 dimensions to give a user-defined perspective of the model eye that is an ideal teaching tool (see Figure 1).

This technology can be integrated into simulators of medical equipment, such as ophthalmoscopes, ultrasound probes, and lasers, to give real time 3D feedback on ophthalmologists' aiming and operation of the equipment and simulate the consequences of their actions, such as measuring distances in ultrasound.

The system can evaluate their technique and compare their performance against a gold standard performed by a competent operator. The system can give them feedback and illustrate the gold standard performance for educational purposes.

\section{Methods}

We have developed a novel approach to teach ocular ultrasound by using a novel 3D ocular model. A 3D virtual model is built using widely available, open source, software (see Figure 2). The model is then used to generate movie clips simulating different orientations of the scanner head. Using Blender, Quicktime motion clips are choreographed and collated into interactive quizzes and other pertinent pedagogical media. The process involves scripting motion vectors, rotation, and tracking, of both the virtual stereo camera and the model.

The resulting sequence is then rendered for twinned right- and left-eye views. Finally, the twinned views are synchronized and combined in a format compatible with the stereo projection apparatus.

The process of making models and the various simulations are detailed further on our website (http://www.abdn. ac.uk/ com168/ophth/development_process.shtml) to illustrate further the potential of our models.

\section{Results and discussion}

The eye models are currently being used to teach ocular ultrasound and they have been made to simulate ultrasound positions and lesion localization (see Figure 3).

These models will help the student with spatial awareness and allow for assimilation of this awareness into clinical practice. It will also help with grasping the nomenclature

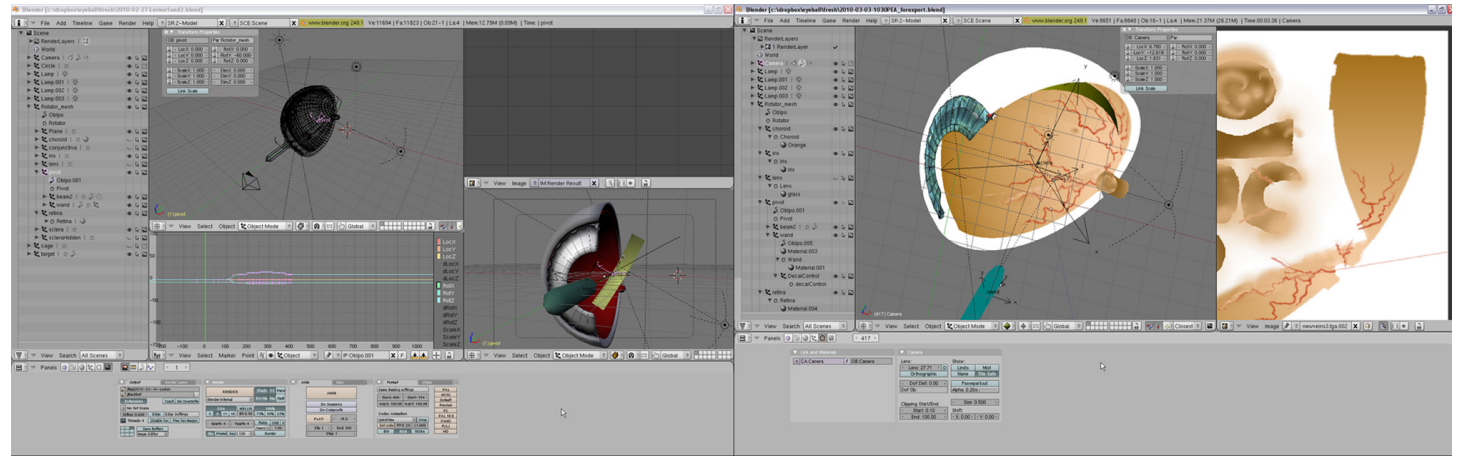

Figure 2 Virtual eye model building in Blender (open source software). 


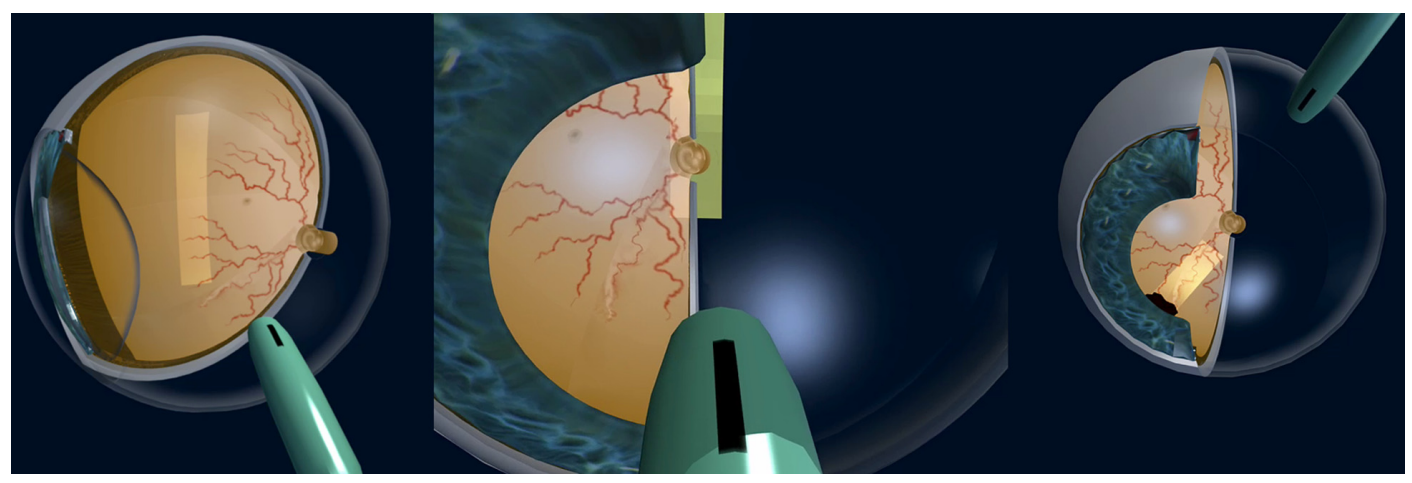

Figure 3 3D eye models displaying different echographic positions and screening of lesions.

used in ocular ultrasound as well as helping with localization of lesions and obtaining the best possible images for echographic diagnosis, accurate measurements, and reporting.

A further model has been developed from our experience and work on eye modeling in Blender. This model is interactive and can be manipulated in any direction and plane using a graphics interface pad.

This model has much potential to teach where both trainer and trainee can interact with it. It will be used to teach not only ultrasound, but also ophthalmic anatomy, and surgical and laser procedures.

\section{Future development}

To date a virtual eye model has been developed (see Figure 4) and used to test the potential for learning enhancement with students of ophthalmology, as detailed Table 1.

Table I Pedagogical applications

\begin{tabular}{|c|c|}
\hline Features & Benefits \\
\hline Real 3D modeling & $\begin{array}{l}\text { Interactive } 3 D \text { anatomically accurate model } \\
\text { to teach medical students and trainee doctors } \\
\text { The model can also be incorporated into } \\
\text { training tools }\end{array}$ \\
\hline $\begin{array}{l}\text { Synchronized video } \\
\text { and ultrasound images }\end{array}$ & $\begin{array}{l}\text { Correlates footage of the patient set-up } \\
\text { and probe position of an experienced } \\
\text { ultrasonographer with the resultant } \\
\text { ultrasound image and the model eye to } \\
\text { demonstrate the technique }\end{array}$ \\
\hline Simulator & $\begin{array}{l}\text { The operator can see in real time and in } 3 D \\
\text { as they practice performing procedure }\end{array}$ \\
\hline Integrated filters & $\begin{array}{l}\text { There is no need to wear glasses to visualize } \\
\text { in } 3 D \text { and the technology can be used to } \\
\text { teach large classes }\end{array}$ \\
\hline Instruction & $\begin{array}{l}\text { The trainee can be guided through the } \\
\text { procedure by an instructor (possible avatar) }\end{array}$ \\
\hline Performance evaluation & $\begin{array}{l}\text { The trainee can be assessed and compare } \\
\text { their performance against a pre-recorded } \\
\text { example of good technique }\end{array}$ \\
\hline
\end{tabular}

\section{Possible hardware integration}

We are currently working on specifying and commissioning a prototype of the hardware and drivers of peripheral devices to control a range of Open Source software such as OpenSceneGraph (OSG) and Blender, thereby allowing realtime manipulation of the virtual eye models in pedagogical scenarios.

\section{Items include}

1. Develop the prototype peripheral hardware and electronics:

a. Globe peripheral and drivers broadcasting the orientation - pitch, yaw, and tilt - the real-time orientation of the globe.

b. Probe peripheral and drivers broadcasting proximity, and orientation of the probe relative to the globe, in real-time.

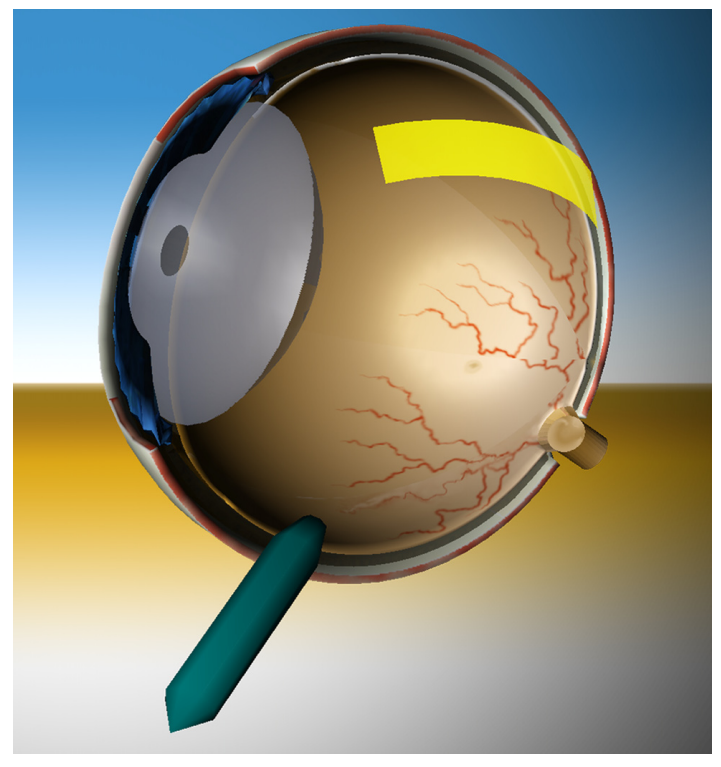

Figure 4 Interactive stereoscopic 3D eye model. 
c. WiFi communication with host computer and OSG tracking module.

2. Interactively develop and field test both drivers' integration with OSG. This involves writing an OSG manipulator module which compiles on Windows, Macintosh, and Linux.

3. Develop and field test software modules utilizing the generated OSG manipulator data on the existing eye model, thereby manipulating and displaying:

a. real-time orientation of the globe model affecting the virtual eye model.

b. real-time orientation of the probe relative to the globe affecting the virtual probe and, ultimately (see 4 below), generating synthesized scanner output.

4. Develop and field test associated ophthalmology teaching and learning modules utilizing these tools, and including refinement of the existing eye model's appearance.

5. Develop a visual synthesizer module for OSG, generating an inset panel within the 3D environment displaying simulated, real-time, ultrasonic scanner output dependent on the probe's position relative to the globe

6. Extend the application display capabilities to 3D spectacles and thus fully immersive 3D augmented reality experiences, for example:

- Within simulated microscope apparatus.

- A multiuser server for small group anatomy tutorials utilizing 3D spectacles. This needs to track each user's head position relative to the assumed location of the virtual model.
7. Evaluate monoscreen-3D display for out-of-hours/library access.

\section{Conclusion}

There is much potential for teaching and learning using these interactive eye models. Further refinement of these models and appropriate hardware integration will allow us to develop this tool for the benefit of teaching ocular ultrasound as well as surgical and laser procedures without having to put patients at risk.

It is important for us to develop this technology further for the benefit of the ophthalmological profession and fraternity.

\section{Disclosure}

The authors disclose no conflicts of interest.

\section{References}

1. Atta HR. Ophthalmic Ultrasound: A Practical Guide. London, UK: Butterworth-Heinemann;1996.

2. Lee D. Virtual reality simulation of the ophthalmoscopic examination. MSc Thesis. University of California of Los Angeles; 1997.

3. Pimentel K, Teixeira K. Virtual Reality: Through the Looking Glass. New York: McGraw-Hill; 1993.

4. Rhodes ML. Computer graphics and medicine: a complex partnership. IEEE Comput Graph Appl. 1997;17(1):22-28.

5. Hunter IW, Jones LA, Sagar MA, Lafontaine SR, Hunter PJ. Ophthalmic microsurgical robot and associated virtual environment. Comput Biol Med. 1995;25(2):173-182.

6. Mostafawy S, Kermani O, Lubatschowski, H. Virtual eye: retinal image visualisation of the human eye. IEEE Comput Graph Appl. 1997;17(1):8-12.
Clinical Ophthalmology

\section{Publish your work in this journal}

Clinical Ophthalmology is an international, peer-reviewed journal covering all subspecialties within ophthalmology. Key topics include: Optometry; Visual science; Pharmacology and drug therapy in eye diseases; Basic Sciences; Primary and Secondary eye care; Patient Safety and Quality of Care Improvements. This journal is indexed on

Submit your manuscript here: http://www.dovepress.com/clinical-ophthalmology-journal

\section{Dovepress}

PubMed Central and CAS, and is the official journal of The Society of Clinical Ophthalmology (SCO). The manuscript management system is completely online and includes a very quick and fair peer-review system, which is all easy to use. Visit http://www.dovepress.com/ testimonials.php to read real quotes from published authors. 